\title{
A UNIFIED DECISION MODEL FOR EVALUATION AND SELECTION OF MES SOFTWARE
}

\author{
Liang Chao ${ }^{1}$, Qing $\mathrm{Li}^{2}$ \\ 'Department of Automation, Tsinghua University, Beijing, China; Email: \\ liangc04@mails.tsinghua.edu.cn. ${ }^{2}$ Department of Automation, TsinghuaUniversity, Beijing, \\ China.
}

Abstract: In this paper, we explore the potential of applying the analytic network process (ANP) to evaluate and select MES software. Different from AHP, ANP allows feedback and interdependence between factors. In our decision model, we consider MES' unique attribute as an information hub related to nearly all of the other information systems. In addition, the relationships among functionalities which MES software performs are also taken into consideration. Finally, we validate the decision model through a test.

Key words: Analytic Network Process (ANP), Manufacturing Execution Systems (MES), Decision Model, Evaluation, Selection.

\section{INTRODUCTION}

Since introduced in 1990, Manufacturing Execution Systems (MES), a category of industrial software for the manufacturing environment, has been adopted in a number of industries. ${ }^{1}$ As increasing manufacturers realize that MES is a key technology for improving manufacturing operation and financial performance in the competitive global marketplace, and want to implement it, how to select the most suitable software inevitably becomes a critical problem encountered by the IT managers or executives

The paper provides a decision model for MES software evaluation and selection based on the analytical network process (ANP). Since MES often

Sponsored by China 863 Program, No. 2001AA415340; Sponsored by China Natural Science Fund, No. 60474060

Please use the following format when citing this chapter:

Chao, Liang, Li, Qing, 2006, in International Federation for Information Processing (IFIP), Volume 207, Knowledge Enterprise: Intelligent Strategies In Product Design, Manufacturing, and Management, eds. K. Wang, Kovacs G., Wozny M., Fang M., (Boston: Springer), pp. 691-696. 
act as an information hub, the decision model not only evaluates the software itself, but also its broad organizational impact.

In the following part of the paper, Section 2 presents the decision model. Introduction of the ANP methodology and its application are provided in sections 3.Finally, we complete the paper with a conclusion.

\section{THE DECISION MODEL FOR MES SOFTWARE SELECTION}

The decision model of this study is shown in Fig.1. The factors considered and relationships among them are described following in detail.

\subsection{Factors considered}

As we know, when we evaluate and select software, we not only need to compare the software performance, but also need to compare the vendor performance, because besides the factors related to software performance, other factors requiring critical consideration, such as cost, implementation time and support, vary dramatically from different vendors. So we divide factors considered into two categories: Software Requirements (SOR) and Vendor Requirements (VER). ${ }^{7}$

For the $S O R$, we consider two clusters of factors:

Functionalities (FUN): MESA International has identified eleven principal functions of MES ${ }^{4}$. Because an individual customer may have individual needs, we can not define the constant functions in the decision model. Here we construct the cluster FUN based on the assumption that a certain customer requires the seven functions as showed in decision model. Of course, we can change the functions in the cluster according to practical needs.

It is the functions that serve plant's needs. Therefore, during evaluating process, we must identify whether and to which extent functionalities of the MES software match the production needs firstly.

Information Technology Requirements (ITR): This cluster relates to technical factors pertaining to the MES.

- Flexibility refers to the extent to which MES can be modified for use in applications or environments. In the fiercely competitive and everchanging society, plants may be required to produce different products to survive, so flexibility is very important for a software system.

- Reliability refers the ability of MES to perform its required functions under stated conditions during the time when it is running

- Compatibility indicates how the MES accommodates with the existing 
and future systems with which it is interacting. Because MES touches nearly all of the other information systems, integration between MES and the other systems is a key to gaining full benefits not only from MES but also from other information systems.

- Security entails the protection of the MES' data and processes. ${ }^{2}$

- Ease of use is defined as the extent to which a prospective user can operate without having to overcome many difficulties. Since MES is mainly operated by workers in plant rather than the professionals, the factor is also considered critically.

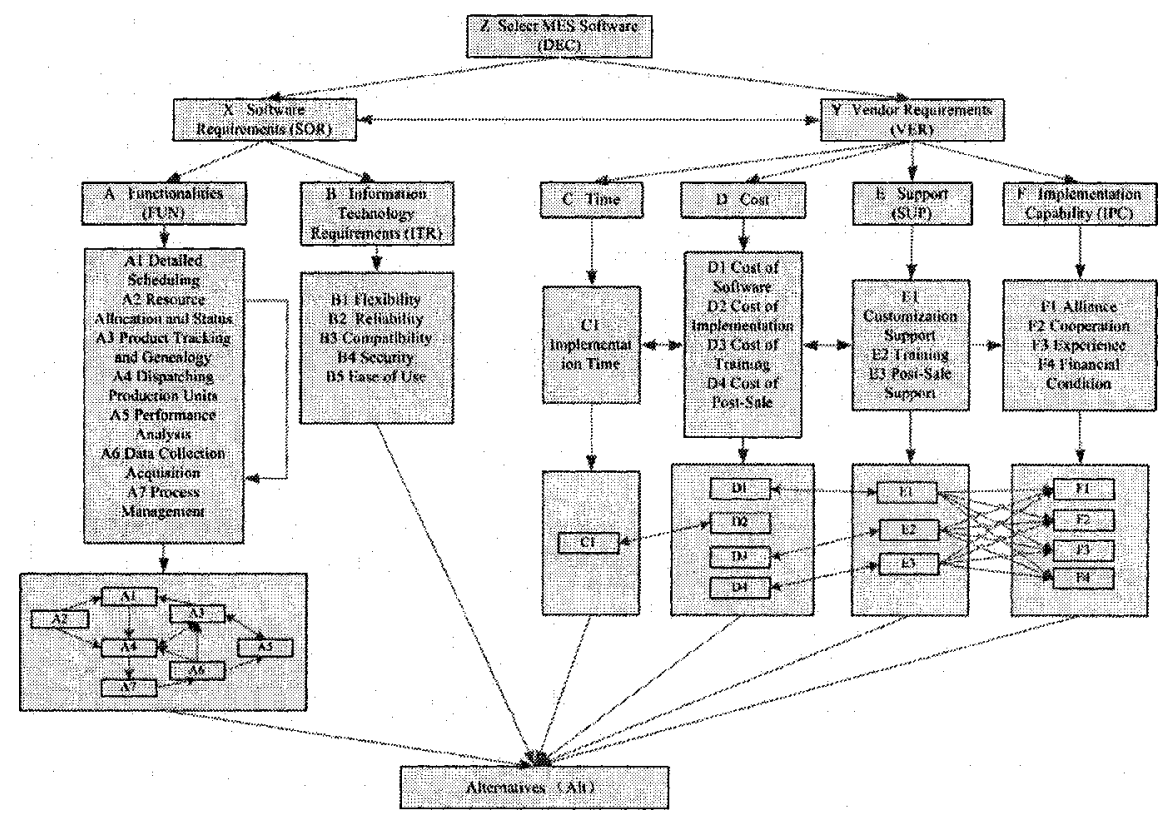

Figure 1. Decision Model for MES Software Selection

For the $V E R$, we consider four clusters of factors:

1) Time: in this cluster we include only one factor

-Implementation Time: since the implementation time for different vendors varies greatly, the factor needs to be considered.

2) Cost: We should consider the total cost rather than only cost of software, because cost of software is only a part or even a small part of the total cost, and other types of cost such as cost of post-sale may account for more portions.

3) Support (SUP): this cluster involves three types of related services provided by vendors. 
- Customization Support refers to the ability of MES vendors to redesign or adjust the software according to customers' practical needs.

-Training indicates the activity provided by vendors to help end-users familiar with and operate the system quickly.

-Post-sale Support involves a series of services during MES whole life cycle, such as maintenance and software upgrade. Since the relationship between customers and vendors is not a short one, and MES affects not only manufacturing operation but also financial performance, the supports would have a potential impact on the company strategy in the long term.

4) Implementation capability (IPC): Cooperation attitude, rich experience, powerful and helpful alliance, and favorable financial condition would help vendors fulfill their promise.

\subsection{Relationships among factors}

Fig. 1 gives the relationships not just among the clusters but also among the factors (if the relationships exist), which is showed in the Fig .1 just below the relationship among clusters.

The hierarchical relationships between $S O R$ and FUN, ITR clusters are easy to justify. So are the hierarchical relationships between the $V E R$ and Time, Cost, SUP, IPC clusters.

In addition to these hierarchical relationships, there are three types of interdependent (two-way)relationships between different clusters, one type of one-way relationship between different clusters, and one type of intradependent (two-way) relationship in the same cluster that require explanation.

Among the three types of interdependent relationships, the first is a twoway relationship between $S O R$ and VER.This relationship is substantiated in that different vendors supply different MES software, and different software requirements lead to different vendors who satisfy the requirements .Our second interrelationship is between Time and Cost clusters, which is due to the interrelationship between $C 1$ and $D 2$ factors, and the interrelationship is easy to prove. The third interrelationship is between Cost and SUP. The relationship indicates the fact that the Supports provided by vendors and the corresponding Cost the Supports charge influence each other.

The one-way relationship is from $S U P$ to $I P C$ cluster. The explanation is that each factor of $I P C$ affects each factor of SUP, in other words, the factors that influence the Implementation Capability (IPC), are also the ones that influence Supports (SUP) the vendor can provide.

The intradependent relationships are among factors of the FUN cluster. Many of these functions logically contribute to each other. For example, Data Collection/Acquisition can provide data to Product Tracking, while 
Performance Analysis feed Product Genealogy. In this model, we depict all the possible relationships among the functions. ${ }^{4,8}$

\section{APPLICATION OF ANP}

ANP is proposed by Thomas L. Saaty ${ }^{6}$, and has been used as a practical method for evaluation and selection in many fields. In this study, to validate the decision model, we invited Mr. Chen to help us to select the best MES software from three alternatives: Alt1, Alt 2 and Alt3. Mr. Chen was an IT manager in a big plant, and he was with over ten years experience as a consultant for enterprise software implementation and integration. The plant was planning to implement MES. After identifying not only the theory and procedure of ANP, but also the factors in each cluster and the relationships among them, under our directions, Mr. Chen made the paired-comparisons in both the cluster and factor level ${ }^{2}$. Based on the preference from Mr. Chen, we compute the priority vectors, and form the initial supermatrix. ${ }^{2,5,6}$ Table 1 provides the overall cluster priorities, each column represents the priorities of the clusters on the left with respect to the controlling cluster on the top of the column. Table 2 shows partial data of the initial supermatrix.

Table 1. Overall cluster priorities

\begin{tabular}{lllllllllll}
\hline & $\mathrm{A}$ & $\mathrm{B}$ & $\mathrm{C}$ & $\mathrm{D}$ & $\mathrm{E}$ & $\mathrm{F}$ & $\mathrm{X}$ & $\mathrm{Y}$ & $\mathrm{Z}$ & Alt \\
\hline $\mathrm{A}$ & 0.75 & 0.00 & 0.00 & 0.00 & 0.00 & 0.00 & 0.60 & 0.00 & 0.00 & 0.00 \\
$\mathrm{~B}$ & 0.00 & 0.00 & 0.00 & 0.00 & 0.00 & 0.00 & 0.20 & 0.00 & 0.00 & 0.00 \\
$\mathrm{C}$ & 0.00 & 0.00 & 0.00 & 0.14 & 0.00 & 0.00 & 0.00 & 0.09 & 0.00 & 0.00 \\
$\mathrm{D}$ & 0.00 & 0.00 & 0.33 & 0.00 & 0.20 & 0.00 & 0.00 & 0.13 & 0.00 & 0.00 \\
$\mathrm{E}$ & 0.00 & 0.00 & 0.00 & 0.43 & 0.00 & 0.00 & 0.00 & 0.22 & 0.00 & 0.00 \\
$\mathrm{~F}$ & 0.00 & 0.00 & 0.00 & 0.00 & 0.40 & 0.00 & 0.00 & 0.19 & 0.00 & 0.00 \\
$\mathrm{X}$ & 0.00 & 0.00 & 0.00 & 0.00 & 0.00 & 0.00 & 0.00 & 0.37 & 0.67 & 0.00 \\
$\mathrm{Y}$ & 0.00 & 0.00 & 0.00 & 0.00 & 0.00 & 0.00 & 0.20 & 0.00 & 0.33 & 0.00 \\
Z & 0.00 & 0.00 & 0.00 & 0.00 & 0.00 & 0.00 & 0.00 & 0.00 & 0.00 & 0.00 \\
Alt & 0.25 & 1.00 & 0.67 & 0.43 & 0.40 & 1.00 & 0.00 & 0.00 & 0.00 & 0.00 \\
\hline
\end{tabular}

Table 2. Initial supermatrix

\begin{tabular}{llllllllllllll}
\hline & $\mathrm{A} 1$ & $\mathrm{~A} 2$ & $\mathrm{~A} 3$ & $\cdots$ & $\mathrm{B} 4$ & $\mathrm{~B} 5$ & $\mathrm{C} 1$ & $\mathrm{D} 1$ & $\cdots$ & $\mathrm{X}$ & $\mathrm{Y}$ & $\cdots$ & Alt3 \\
\hline $\mathrm{A} 1$ & 0.00 & 0.50 & 0.54 & $\cdots$ & 0.00 & 0.00 & 0.00 & 0.00 & $\cdots$ & 0.28 & 0.00 & $\cdots$ & 0.00 \\
$\mathrm{~A} 2$ & 0.00 & 0.00 & 0.00 & $\cdots$ & 0.00 & 0.00 & 0.00 & 0.00 & $\cdots$ & 0.11 & 0.00 & $\cdots$ & 0.00 \\
$\mathrm{~A} 3$ & 0.00 & 0.00 & 0.00 & $\cdots$ & 0.00 & 0.00 & 0.00 & 0.00 & $\cdots$ & 0.11 & 0.00 & $\cdots$ & 0.00 \\
$\cdots$ & $\cdots$ & $\cdots$ & $\cdots$ & $\cdots$ & $\cdots$ & $\cdots$ & $\cdots$ & $\cdots$ & $\cdots$ & $\cdots$ & $\cdots$ & $\cdots$ & $\cdots$ \\
$\mathrm{B} 4$ & 0.00 & 0.00 & 0.00 & $\cdots$ & 0.00 & 0.00 & 0.00 & 0.00 & $\cdots$ & 0.12 & 0.00 & $\cdots$ & 0.00 \\
$\mathrm{~B} 5$ & 0.00 & 0.00 & 0.00 & $\cdots$ & 0.00 & 0.00 & 0.00 & 0.00 & $\cdots$ & 0.07 & 0.00 & $\cdots$ & 0.00 \\
$\mathrm{C} 1$ & 0.00 & 0.00 & 0.00 & $\cdots$ & 0.00 & 0.00 & 0.00 & 0.00 & $\cdots$ & 0.00 & 1.00 & $\cdots$ & 0.00 \\
$\mathrm{D} 1$ & 0.00 & 0.00 & 0.00 & $\cdots$ & 0.00 & 0.00 & 0.00 & 0.00 & $\cdots$ & 0.00 & 0.29 & $\cdots$ & 0.00 \\
$\cdots$ & $\cdots$ & $\cdots$ & $\cdots$ & $\cdots$ & $\cdots$ & $\cdots$ & $\cdots$ & $\cdots$ & $\cdots$ & $\cdots$ & $\cdots$ & $\cdots$ & $\cdots$
\end{tabular}




\begin{tabular}{llllllllllllll}
\hline & $\mathrm{A} 1$ & $\mathrm{~A} 2$ & $\mathrm{~A} 3$ & $\cdots$ & $\mathrm{B} 4$ & $\mathrm{~B} 5$ & $\mathrm{C} 1$ & $\mathrm{D} 1$ & $\cdots$ & $\mathrm{X}$ & $\mathrm{Y}$ & $\cdots$ & $\mathrm{Alt} 3$ \\
\hline $\mathrm{X}$ & 0.00 & 0.00 & 0.00 & $\cdots$ & 0.00 & 0.00 & 0.00 & 0.00 & $\cdots$ & 0.00 & 1.00 & $\cdots$ & 0.00 \\
$\mathrm{Y}$ & 0.00 & 0.00 & 0.00 & $\cdots$ & 0.00 & 0.00 & 0.00 & 0.00 & $\cdots$ & 1.00 & 0.00 & $\cdots$ & 0.00 \\
$\cdots$ & $\cdots$ & $\cdots$ & $\cdots$ & $\cdots$ & $\cdots$ & $\cdots$ & $\cdots$ & $\cdots$ & $\cdots$ & $\cdots$ & $\cdots$ & $\cdots$ & $\cdots$ \\
Alt3 & 0.21 & 0.50 & 0.21 & $\cdots$ & 0.40 & 0.44 & 0.16 & 0.40 & $\cdots$ & 0.00 & 0.00 & $\cdots$ & 0.00 \\
\hline
\end{tabular}

After normalizing the initial supermatrix by multiplying it by the corresponding elements in Table 1, and raising the multiplicative resulting to a high power, ${ }^{2,5,6}$ we obtain the final priorities of the alternatives as following: Alt $1=0.469$, Alt $2=0.232$, Alt $3=0.299$

Obviously, Alt 1 is the MES software recommended for selection in our study. Mr. Chen told us that Alt 1 was just the one which he considered to be most favorable before the test, and the results agreed with his former assessments by and large.

According to feedbacks from Mr. Chen, the decision model is helpful for potential customers to make their selection of MES, and it is a practical way to apply ANP in this model, though the process is somewhat tiring.

\section{CONCLUSION AND SUMMARY}

In this paper, we explore the potential of applying the ANP technique to evaluate and select the MES software. The evaluation and decision model provides a systematic view of the alternatives. Based on the ANP technique, the decision-making process is lucid.

However, we must point out that the underlying assumption in this paper is that manufacturers have decided to invest in MES, if it is not the case, more consideration would be required.

\section{REFERENCE}

1. The Benefits of MES: A Report from the Field, MESA international, White Paper No.1, May, 1997.

2. J. Sarkis and R.P. Sundarraj, Evaluation of Enterprise Information Technologies: A Decision Model for High-Level Consideration of Strategic and Operational Issues, IEEE Trans. on Systems, Man, and Cybernetics-Part C Volume, Issue 99,2005 pp.1 - 14.

3. Controls Definition \& MES to Controls Data Flow Possibilities, MESA international, White Paper No.3, February, 2000.

4. MES Explained: A High Level Vision, MESA international, White Paper No.6,9, 1997.

5. T. L. Saaty, Fundamentals of Decision Making and Priority Theory with the Analytic Hierarchy Process, Pittsburgh, PA: RWS, 1994.

6. T. L. Saaty, Decision Making With Dependence and Feedback: The Analytic Network Process, Pittsburgh, PA: RWS, 1996.

7. MES Software Evaluation / Selection, MESA international, White Paper No.4, 1996.

8. International Standard IEC/WD 62264-3, Enterprise-control system integration -Part 3: Activity models of manufacturing operations management. 